\title{
As Práticas de Endomarketing e a Percepção dos Funcionários de uma Empresa do Ramo Varejista de Móveis e Eletrodomésticos de Manaus
}

The Practices of Endomarketing and the Perception of the Employees of a Company of the Furniture and Household Appliances Retailer of Manaus

Las Prácticas de Endomarketing y la Percepción de los Empleados de una Empresa del Sector Minorista de Muebles y Electrodomésticos de Manaus

Fernanda Barbosa Rodrigues ${ }^{1}$ barbosafernanda@outlook.com

Armando Araújo de Souza Júnior ${ }^{1}$ armando-jr07@bol.com.br http://lattes.cnpq.br/4819744809032210 https://orcid.org/0000-0003-2950-1434

Universidade Federal do Amazonas, UFAM, Brasil ${ }^{1}$ 
As Práticas de Endomarketing e a Percepção dos Funcionários de uma Empresa do Ramo Varejista de Móveis e Eletrodomésticos de Manaus

\title{
Resumo
}

Este artigo apresenta um estudo sobre o impacto das políticas de endomarketing sobre o engajamento de funcionários. O objetivo geral do artigo foi avaliar a influência das práticas de endomarketing sob a ótica dos colaboradores de uma empresa do ramo varejista de móveis e eletrodomésticos na cidade de Manaus. Para tanto, foi realizada uma pesquisa de natureza qualitativa cujo os dados foram coletados a partir de entrevista com roteiro semiestruturado junto a 5 funcionários que atuam em duas lojas situadas em shoppings da cidade de Manaus. A técnica utilizada para interpretação dos discursos dos indivíduos foi a análise de conteúdo. Os resultados demonstram que a empresa utiliza a comunicação interna como principal estratégia de endomarketing, realizando reuniões periódicas com a equipe de trabalho e disponibilizando diversas ferramentas conectadas à internet com atualização em tempo real. Também foi possível verificar que os funcionários têm seus ofícios diretamente impactados pelo uso das ferramentas, bem como há perceptível melhora no clima organizacional do ambiente de trabalho, causada pela facilitação e incentivo a comunicação frequente entre os colaboradores. As práticas de endomarketing analisadas neste estudo poderão servir como referências para novos aprofundamentos no âmbito da comunicação interna e engajamento de funcionários.

Palavras-Chaves: Endomarketing. Comunicação Interna. Engajamento.

\section{The Practices of Endomarketing and the Perception of the Employees of a Company of the Furniture and Household Appliances Retailer of Manaus}

\begin{abstract}
This article presents a study about the impact of the endomarketing policy upon the employee engagement. The main objective of the article was to evaluate the influence of endomarketing practices from the perspective of the employees of a retail and furniture company in the city of Manaus. For this purpose, a qualitative research was carried out, whose data were collected from a semi-structured interview with 5 employees who work in two stores located inside shopping malls in the city of Manaus. The technique used to interpret individuals' discourses was content analysis. The results demonstrated that the company uses internal communication as the main endomarketing strategy, conducting periodic meetings with the work team and providing several tools connected to the internet with real-time updating. It was also possible to verify that the employees have their offices directly impacted by the use of those tools, as well as there is a perceptible improvement in the organizational climate of the work environment, caused by the facilitation and the frequent communication among employees. The endomarketing practices analyzed in this study may serve as references for further research in the field of internal communication and employee engagement.
\end{abstract}

Key-words: Endomarketing. Internal Communication. Engagement.

\section{Las Prácticas de Endomarketing y la Percepción de los Empleados de una Empresa del Sector Minorista de Muebles y Electrodomésticos de Manaus}

\section{Resumen}


As Práticas de Endomarketing e a Percepção dos Funcionários de uma Empresa do Ramo Varejista de Móveis e Eletrodomésticos de Manaus

Este artículo presenta un estudio sobre el impacto de las políticas de endomarketing sobre el compromiso de los empleados. El objetivo general del artículo fue evaluar la influencia de las prácticas de endomarketing bajo la óptica de los colaboradores de una empresa del sector minorista de muebles y electrodomésticos en la ciudad de Manaus. Para ello, se realizó una investigación de naturaleza cualitativa cuyos datos fueron recolectados a partir de una entrevista con un itinerario semies estructurado junto a 5 funcionarios que actúan en dos tiendas ubicadas en centros comerciales de la ciudad de Manaus. La técnica utilizada para la interpretación de los discursos de los individuos fue el análisis de contenido. Los resultados demuestran que la empresa utiliza la comunicación interna como principal estrategia de endomarketing, realizando reuniones periódicas con el equipo de trabajo y ofreciendo diversas herramientas conectadas a internet con actualización en tiempo real. También fue posible verificar que los funcionarios tienen sus oficios directamente impactados por el uso de las herramientas, así como hay perceptible mejora en el clima organizacional del ambiente de trabajo, causada por la facilitación e incentivo a la comunicación frecuente entre los colaboradores. Las prácticas de endomarketing analizadas en este estudio pueden servir como referencias para nuevas profundidades en el ámbito de la comunicación interna y el compromiso de funcionarios.

Palabras Clave: Endomarketing. Comunicación Interna. Compromiso. 
As Práticas de Endomarketing e a Percepção dos Funcionários de uma Empresa do Ramo Varejista de Móveis e Eletrodomésticos de Manaus

\section{INTRODUÇÃO}

A comunicação é de vital importância para a perenização de uma empresa, pois está diretamente ligada ao seu dinamismo e organicidade, funções que asseguram a adaptabilidade a mercados, inovações tecnológicas e crescimento, onde somente a comunicação eficaz torna seus processos viáveis (Pimenta, 2004; Patrick \& Bruce, 2010 apud Reis; Brugnerotto; Sevilha; Cremonesi; Oswaldo, 2018). Em relação a convivência e desenvolvimento de atividades, bem como para o alcance de consensos, a adoção do diálogo mostra-se como a melhor alternativa a ser utilizada na resolução de impasses e conflitos, levando o entendimento da comunicação além da esfera técnica (Marchiori, 2008; Matos, 2009).

Atualmente, um dos desafios encontrados nas organizações é a retenção de pessoas. Com índices de rotatividade altos, empresas que antes focavam apenas no cliente externo, buscam também considerar dentro da sua estratégia de marketing o cliente interno, pois o que realmente cria a diferenciação e o valor no mercado é o capital humano pertencente a uma empresa (Rodrigues, 2017).

O endomarketing, etimologicamente "marketing interno", foi introduzido no Brasil por Bekin em 1991, quando registrou a marca junto ao Instituto Nacional da Propriedade Intelectual INPI. O conceito, inicialmente entra no cenário empresarial como uma técnica de gerar comprometimento em relação aos objetivos da empresa, usando ferramentas de marketing para promover valores referentes a satisfação do cliente, que neste caso, são os funcionários (Bekin, 1995).

O tema ganhou uma abordagem mais voltada ao gerenciamento de pessoas, uma vez que o funcionário deixa de ser visto como gasto e passa a ser encarado como recurso, formando assim o capital humano (Mendes, 2004; José \& Rosa, 2012). Dessa forma, o endomarketing passa a ser um tema que entra também na pauta da área da gestão de pessoas e recursos humanos. Nessa ótica, Brum (2010) diz que o endomarketing é utilizado com o objetivo de motivar e criar consciência empresarial nos funcionários, gerando um clima organizacional agradável, a fim de que o colaborador ajude na consolidação de imagem e valor para uma empresa.

No tocante a técnica de gerar motivação e incentivar funcionários, estudos como Chaves, França \& Carvalho (2013), Paschini (2015) e Rodrigues (2017) afirmam que a prática do endomarketing é positiva para manutenção do clima organizacional. Outra abordagem encontrada é a do endomarketing como ferramenta de fidelização do cliente interno, apresentada em estudos como Barth \& Negri (2012) e Duarte (2014), que aduzem melhorias nos níveis de engajamento e produtividade de funcionários que trabalham em empresas que possuem práticas relacionadas ao tema. Finalmente, a utilização do endomarketing como estratégia de gestão, que aparece em José \& Rosa (2012), Santos, Almeida \& Feitosa (2016), e Raquel (2016), onde a utilização deste como política empresarial proporciona um cenário positivo, implicando em crescimento para a organização.

Nessa direção, o objetivo geral deste artigo foi avaliar a influência das práticas de endomarketing sob a ótica dos colaboradores de uma empresa do ramo varejista de móveis e eletrodomésticos na cidade de Manaus. 
As Práticas de Endomarketing e a Percepção dos Funcionários de uma Empresa do Ramo Varejista de Móveis e Eletrodomésticos de Manaus

Este artigo está dividido em seis partes, sendo esta primeira parte a introdução, seguida de revisão teórica abordando o tema, a metodologia utilizada para a realização do estudo, os resultados obtidos na pesquisa, as conclusões e por último, as referências utilizadas para dar suporte teórico ao estudo.

\section{FUNDAMENTAÇÃO TEÓRICA}

\subsection{Marketing}

O termo Marketing começou a ser utilizado na American Marketing Association - AMA, em 1930. No Brasil, apenas na década de 50, o termo começou a ser apresentado em multinacionais vindas da Europa ou América do Norte. A palavra nunca ganhou uma tradução exata no português para transparecer todo seu conceito, uma vez que etimologicamente, a tradução "mercadologia" diz respeito ao estudo do mercado, o que não engloba o sistema de Marketing como um todo (Pinho, 2012).

Em termos de historicidade e evolução, Las Casas (2009), Pinho (2012) e Duarte (2014) apresentam uma divisão da orientação das organizações em três fases, sendo estas:

- Orientação para a Produção, onde sob a influência da Revolução Industrial, a principal prioridade era garantir os meios de produção, como matéria-prima, mão de obra e capital, uma vez que o público-alvo da época possuía pouco poder aquisitivo, limitando-se assim a atender apenas as suas necessidades mais básicas;

- Orientação para Vendas, com o crescimento da atividade industrial e o aumento da capacidade de produção, a concorrência aumentou exponencialmente, assim, gestores passaram a investir em técnicas de distribuição, promoção e vendas muito mais agressivas a fim de aumentarem seus lucros obtidos;

- Orientação para o mercado, com a diminuição da demanda e cada vez maiores níveis de oferta de bens, o consumidor passa a optar por aquele produto que melhor atenda suas expectativas.

Diante da evolução do tema exposto anteriormente, encontra-se um desafio: como equilibrar os níveis de produção com o consumo do mercado. Daí vem o conceito de marketing, que conforme Ogden \& Crescitelli (2007, p. 1):

É a ciência que estuda, entende e monitora mercados [...] e estabelece que uma empresa deve satisfazer os desejos e necessidades do consumidor em troca de lucro, em outras palavras, a empresa ou organização deve direcionar todos os seus esforços a fim de dar a seus clientes serviços e produtos que eles desejam ou de que necessitam.

Sob a mesma ótica, Silva, Neto \& Mota (2017) acrescentam que além de atender necessidades, o marketing também tem a finalidade de orientar a elaboração de produtos e serviços, bem como guiar o direcionamento e abordagem de mercado, tudo com o objetivo de buscar a satisfação do cliente final, a melhoria do atendimento e do desempenho da organização.

Por sua vez, Cobra (2011) destaca que o marketing deve ser um código de conduta para a empresa, onde as características dos produtos e serviços a serem elaborados e ofertados advêm do suprimento das necessidades latentes dos consumidores, e cujo objetivo é buscar o equilíbrio com a satisfação mútua de metas da empresa. 
As Práticas de Endomarketing e a Percepção dos Funcionários de uma Empresa do Ramo Varejista de Móveis e Eletrodomésticos de Manaus

Contudo, atualmente, o conceito desenvolvido de marketing ultrapassa o objetivo exclusivo de suprir necessidades do cliente. A diferenciação do bem através da geração e agregação de valor, e superar a expectativa do cliente já é uma expansão do conceito de marketing (Ogden \& Crescitelli, 2007; Duarte, 2014).

Sob esta ótica, tem-se que o marketing é uma ferramenta que consiste em criar, comunicar e entregar valor, a fim de favorecer o relacionamento da organização com o cliente, proporcionando controle e tornando-o favorável (Kotler, 2000 apud Silva et al., 2017).

De acordo com Kotler e Keller (2006), dentro do espectro vasto das áreas de atuação do marketing, está o Marketing de Relacionamento, e consiste na criação e manutenção de relacionamentos com as partes-chaves, a fim de assegurar a longevidade dessas ligações, que podem ser econômicas, técnicas e sociais. O objetivo é buscar a satisfação na interação da empresa não somente com clientes, como também com fornecedores, distribuidores, revendedores, acionistas, investidores e funcionários, ou seja, todos que estão envolvidos com a organização.

Pinho (2012) define ainda conceitos para o marketing em sua aplicação social, industrial e política, conforme segue:

\begin{tabular}{|c|l|}
\hline Quadro 1 - Aplicações do Marketing \\
\hline $\begin{array}{c}\text { Aplicação do } \\
\text { Marketing }\end{array}$ & \multicolumn{1}{c|}{ Conceituação } \\
\hline Marketing social & $\begin{array}{l}\text { Criado para contribuir com as campanhas de cunho social, } \\
\text { ajudando na aceitabilidade das ideias, na disseminação de } \\
\text { informação e na efetividade da empreitada, com foco em } \\
\text { planejamento de produto e comunicação. }\end{array}$ \\
\hline Marketing Industrial & $\begin{array}{l}\text { Criado para auxiliar na interpretação das necessidades e } \\
\text { expectativas do consumidor industrial, de modo que bens e } \\
\text { serviços são utilizados para gerar novos produtos, tendo seu } \\
\text { foco na promoção, distribuição e assistência pós-venda. }\end{array}$ \\
\hline Marketing Político & $\begin{array}{l}\text { Criado para atuar em campanhas eleitorais, de modo a } \\
\text { traduzir expectativas e intenções, tendo seu foco na } \\
\text { comunicação e promoção. Pode ser utilizado também em } \\
\text { ONGs. }\end{array}$ \\
\hline
\end{tabular}

Fonte: Pinho, 2012, p. 23 e 24.

Em contraste, Kruger, Santos, Torres, Lima \& Martins (2016) afirmam que o marketing está alinhado com o Planejamento Estratégico, uma vez que o processo de marketing de uma empresa orienta a construção deste. Da mesma forma, McCarthy \& Perreault (1997) apud Seitz (2005, p. 94), definem que "os planos do departamento de marketing não são os planos de toda a empresa, por outro lado, os planos da empresa devem ser orientados para marketing”.

O plano estratégico de marketing de uma empresa deve ser relevante, contendo informações objetivas, indicando estratégias ideais e secundárias a serem seguidas. Este deve ser específico e mensurável, contendo indicadores de desempenho. A linguagem deve ser sempre simples e clara, mas sem deixar de ser assertiva e comprometida. Uma boa maneira de gerar engajamento 
As Práticas de Endomarketing e a Percepção dos Funcionários de uma Empresa do Ramo Varejista de Móveis e Eletrodomésticos de Manaus

para a execução efetiva do plano estratégico de marketing é envolver toda a equipe de trabalho em sua elaboração e posterior acompanhamento por meio do feedback (Seitz, 2005).

\subsection{Endomarketing}

Os primeiros movimentos do que viria a ser chamado de endomarketing no Brasil se deram nos anos 80, ocasionados pela observação da inexistência de interação entre gestor e funcionários, e conseguinte questionamento a respeito dos impactos dessa situação para o clima organizacional da instituição (Rodrigues, 2017). A partir daí se deu maior atenção a abordagem de que o cliente interno satisfeito possui motivação para conquistar e fidelizar os clientes externos, aumentando assim a competitividade de uma empresa (Mendes, 2004; Barth \& Negri, 2012; Rodrigues, 2017)

O termo endomarketing só foi registrado no Brasil na década de 90, ocasião em que foi conceituado como ações gerenciadas de marketing, que observam condutas comunitárias e ambientais e que são voltadas para o público interno de toda organização (Bekin, 1995). O conteúdo do endomarketing foi desenvolvido por conta da necessidade de uma melhor comunicação entre pessoas, lide funcionários, e os departamentos, sempre enfocando os objetivos organizacionais de forma a unificar e padronizar os processos de comunicação da empresa (Rodrigues, 2017).

O próprio criador do termo "endomarketing", Bekin (1995), explica que este configura-se na aglutinação do prefixo "endo" que originado do grego significa "interno, para dentro", à palavra "marketing". Dessa forma, o endomarketing, em tradução literal, significa marketing interno ou marketing voltado para dentro. Como o marketing convencional, está baseado na comunicação, mas diferentemente deste, o foco não é no consumidor e sim no colaborador.

Pasquini (2015) faz um paralelo entre a definição de marketing e endomaketing quando afirma que marketing são atividades de planejamento, realização, concepção de ideias que cerne o desejo dos clientes, e que no endomarketing, os clientes na verdade são os funcionários e colaboradores da organização.

Rodrigues (2017, p. 68), diz que os principais objetivos do endomarketing são:

[...] atrair, desenvolver e reter talentos na empresa, melhorar as atitudes e os comportamentos dos colaboradores com relação ao trabalho, introduzir novos produtos, atividade e campanhas de marketing para o seu público interno, estimular em todos a aceitação da missão, visão, valores e objetivos da empresa, como também o treinamento de seus colaboradores.

Brum (2010) e José \& Rosa (2012) aduzem que o endomarketing configura uma das principais estratégias de gestão de pessoas, adotadas por empresas que buscam o sucesso constante e a permanência no mercado. Dessa maneira, pode-se afirmar que a prática do endomarketing consiste no convencimento positivo a respeito da empresa tendo seus funcionários como público-alvo, aliado a práticas de gestão de pessoas.

Brum (2010) conceitua o endomarketing como esforços que uma organização faz a fim de manter relações positivas com seus colaboradores, sendo esta duradoura, produtiva e saudável, 
As Práticas de Endomarketing e a Percepção dos Funcionários de uma Empresa do Ramo Varejista de Móveis e Eletrodomésticos de Manaus

tendo impacto direto na construção da imagem da empresa e agregando valor de mercado para a mesma.

\begin{abstract}
Portanto, na perspectiva sociológica, a identidade é construída. Se olharmos no interior das organizações, não é diferente. A identidade é formada e mantida pelos membros que ali compartilham, discutem e determinam caminhos que a empresa deseja seguir. Ou seja, a construção do conceito "quem somos" é uma visão real, praticada pelas pessoas que fazem a organização (Marchiori, 2008, p. 44).
\end{abstract}

José \& Rosa (2012) e Pasquini (2015), afirmam que uma estratégia de endomarketing, quando bem elaborada, e alinhada a um plano de ação completo, automaticamente gera conhecimento e leva a ações que possibilitam valorização e reconhecimento do funcionário, garantindo sua permanência e lealdade a empresa.

Todavia, a utilização do endomarketing aparece como uma ferramenta que quando é corretamente utilizada, proporciona o alcance de resultados positivos, consolidando a empresa, cada vez mais, como exemplo de excelência perante o mercado competitivo (Feitosa, Santos \& Almeida, 2016).

Dessa forma, parte das organizações presentes no mercado reconhecem que só é possível alcançar o cliente externo a partir da conquista do cliente interno da empresa, sendo esta imprescindível, justificando o contexto de surgimento do endomarketing (Reis et al., 2018).

Em adição, Honorato (2004, p. 24) aduz que "A satisfação dos funcionários é a satisfação dos clientes". O autor coloca ainda que o marketing interno é de fundamental importância para a gestão estratégica de marketing de uma empresa, uma vez que seus próprios funcionários são quem fazem todo o processo acontecer, e são quem tem o contato direto com o cliente final, passando assim uma imagem da empresa ao mercado consumidor. "Torna-se difícil satisfazer os desejos e as necessidades dos clientes externos sem a satisfação dos clientes internos, pois é a partir destes que as relações com os clientes serão duradouras" (Honorato, 2004, p. 24).

Cerqueira (2005) citado por Reis et al. (2018, p. 132) diz que :

\begin{abstract}
Ainda nesta linha de raciocínio, cita que o endomarketing tem como objetivo propagar a cultura da empresa de maneira homogênea; fazendo com que todos os colaboradores, independentemente do nível que se encontrem, compartilhem dos mesmos valores. Ele entende que este é um processo holístico e interativo, onde os reflexos desta prática irão se estender ao nível familiar e social do colaborador e que as consequências serão refletidas em motivação, comprometimento e aumento da produtividade e qualidade de serviços e bens.
\end{abstract}

Feitosa et al. (2016) citam que poucas empresas nacionais investem em técnicas de aprimoramento da relação para com o funcionário, enfocando seus esforços apenas em inovação tecnológica e marketing externo, considerando apenas a demanda do mercado, e desconsiderando o ambiente interno. A implantação da prática do endomarketing dentro de uma empresa promove o fortalecimento dessa relação entre funcionário e empresa.

\title{
2.3 Comunicação Interna
}

A comunicação é fator primordial para a interação humana, onde sua inexistência tornaria impossível as relações estabelecidas entre grupos humanos, seja esta relação comercial, afetiva ou de trabalho. Segundo sua etimologia, a palavra "comunicação" vem de "tornar comum", 
As Práticas de Endomarketing e a Percepção dos Funcionários de uma Empresa do Ramo Varejista de Móveis e Eletrodomésticos de Manaus

dessa forma, conseguir passar a informação de uma pessoa para a outra e realizar o fenômeno da comunicação (Pimenta, 2004).

Angeloni (2010) afirma que para o êxito da comunicação e para que ocorra a tomada de decisões dentro de uma organização, é de extrema importância que se entenda a diferença entre os conceitos de dado, informação e conhecimento. Dessa forma, a autora propõe a seguinte definição para os termos:

\begin{tabular}{|l|l|}
\hline \multicolumn{1}{|c|}{ Quadro 2 - Elementos constituintes da comunicação } \\
\hline Dados & \multicolumn{1}{c|}{ Conceito } \\
\hline Informações & $\begin{array}{l}\text { São elementos brutos, sem significados, desvinculados da } \\
\text { realidade. Eles constituem-se na matéria prima da informação. }\end{array}$ \\
\hline Conhecimentos & $\begin{array}{l}\text { São dados com significado, dotados de relevância e propósito. São } \\
\text { dados contextualizados que visam fornecer uma solução para uma } \\
\text { determinada situação de decisão. }\end{array}$ \\
\hline $\begin{array}{l}\text { Podem ser considerados como as informações processadas pelos } \\
\text { indivíduos. O valor agregado à informação depende dos } \\
\text { conhecimentos anteriores dos mesmos. }\end{array}$ \\
\hline
\end{tabular}

Fonte: Angeloni, 2010, p. 11

Verifica-se, portanto, que a comunicação entre dois ou mais indivíduos é formada por dados, que se transformam em informações, que por sua vez, alinhadas a experiência do receptor, transformam-se em conhecimentos. O conhecimento decorrente da comunicação é de fundamental importância para a tomada de decisões dentro da organização (Silveira \& Felizola, 2009).

A empresa deve internalizar a ideia de que seu posicionamento a respeito da comunicação interna deve ir além do simples repasse de informações, e deve concentrar-se na abertura de diálogo com seus grupos de interesse, bem como com o monitoramento das informações repassadas acerca da sua qualidade (Marchiori, 2008).

Ainda segundo Marchiori (2008, p. 30) "é preciso que os profissionais atuem no sentido de 'construir fatos' no interior de uma organização, e não apenas pautar suas ações na comunicação de fatos que já ocorreram. " Assim, é necessário cogitar as experiências dos profissionais, pois é a sua vivência que o capacita para o trabalho, tendo a comunicação um papel crucial na formação do mesmo.

Na visão de Pimenta (2004), a comunicação dentro de empresas pode ser ainda mais complicada, uma vez que não existem laços afetivos entre aqueles que a exercem. Ainda que exista a neutralidade e racionalidade como pontos favoráveis ao sucesso da comunicação, fatores intrínsecos as organizações como autoridade, níveis organizacionais e sobrecarga, acabam se tornando empecilhos no exercício de uma comunicação sem ruídos.

Patrick \& Bruce (2010) apud Reis et al. (2012) e Rodrigues (2017) colocam que a comunicação interna deve ter clareza e objetividade, visando o entendimento integral das metas pessoais e empresariais, elucidando o papel do indivíduo, evitando ruídos e estimulando o feedback, para que não haja risco de ineficiência, acarretando improdutividade e desmotivação. 
As Práticas de Endomarketing e a Percepção dos Funcionários de uma Empresa do Ramo Varejista de Móveis e Eletrodomésticos de Manaus

\section{METODOLOGIA}

O objetivo geral deste artigo foi avaliar a influência das práticas de endomarketing sob a ótica dos colaboradores de uma empresa do ramo varejista de móveis e eletrodomésticos na cidade de Manaus. Para tanto, optou-se por utilizar a estratégia de pesquisa qualitativa.

A abordagem qualitativa foi adotada nesta pesquisa, a fim de permitir comparação por meio dos dados levantados, e das técnicas adotadas que permitem descrever, traduzir e expressar o sentido dos fenômenos estudados.

Segundo Matias-Pereira (2012), a pesquisa qualitativa é descritiva, pois tem o seu foco no fenômeno e no seu significado, uma vez que é considerado que existe relação dinâmica e indissociável entre o mundo e o sujeito com sua subjetividade. Já para Barros \& Lehfeld (2014) a pesquisa qualitativa consiste na apresentação de dados de forma não numérica, a citar, verbal e discursiva, a fim de descrever o objeto de estudo.

De acordo com a estratégia adotada para a pesquisa, será desenvolvido uma pesquisa de campo de natureza exploratória. Para Santos \& Filho (2017), a pesquisa de campo tem o objetivo de observar os fenômenos exatamente como ocorrem, tendo o contato direto com os elementos envolvidos e permitindo assim a sua análise. De acordo com Matias-Pereira (2012) e Marconi \& Lakatos (2017), a pesquisa exploratória é uma investigação que visa aumentar a familiaridade do pesquisador com o fenômeno, guiar a formulação de hipóteses, e gerar, modificar ou reestabelecer conceitos.

O instrumento de coleta de dados utilizado foi a entrevista com roteiro semiestruturado. Segundo Miguel (2010), a técnica de entrevista tem o propósito de, além de avaliar e testar hipóteses, também proporcionar a compreensão da experiência do indivíduo e tornar perceptível o significado que o sujeito atribui a situação em questão.

Nessa direção, Santos \& Filho (2017) acrescentam que a presença do entrevistador permite ao entrevistado sentir-se seguro para expressar de forma acurada o sentimento a respeito da matéria do estudo, uma vez que um questionário somente pode não ser suficiente para alcançar a realidade buscada e o entrevistador como parte integrante da pesquisa pode elucidar dúvidas e incertezas quanto a natureza e objetivos das questões.

O roteiro semiestruturado permite ao pesquisador organizar um conjunto de questões a serem formuladas junto aos sujeitos da pesquisa, ao mesmo tempo que permite e incentiva que o sujeito fale livremente sobre o objeto de estudo, possibilitando a captação de informações novas e o surgimento de desdobramentos do tema (PÁDUA, 2016).

Como sujeitos da pesquisa, foram selecionados cinco funcionários do nível operacional de uma loja varejista do ramo móveis, eletrodomésticos e eletrônicos da cidade de Manaus, que estão expostos e são alvos das campanhas de endomarketing para motivação dos colaboradores desta empresa. Os sujeitos da pesquisa foram selecionados por conveniência e acessibilidade.

Os dados coletados por meio das entrevistas serão organizados e categorizados por meio da análise de conteúdo. A análise de conteúdo segundo Bardin (2011) consiste em um método de 
As Práticas de Endomarketing e a Percepção dos Funcionários de uma Empresa do Ramo Varejista de Móveis e Eletrodomésticos de Manaus

analisar as comunicações, através de procedimentos sistemáticos, com o objetivo de obter indicadores que permitam a formulação de conhecimentos relativos a essas mensagens.

Corroborando, Câmara (2013) acrescenta que a técnica de pesquisa da análise de conteúdo utiliza os fragmentos das mensagens como forma de detectar implicações ao sentido da comunicação, de modo que o pesquisador deve compreender o sentido da comunicação e também buscar outros significados implícitos ao contexto da transmissão de informação.

Para manter a confidencialidade dos entrevistados, os mesmos foram categorizados como: E1, E2, E3, E4 e E5.

\section{RESULTADOS DA PESQUISA}

Inicialmente, foram coletados alguns dados pessoais dos cinco funcionários da empresa (três homens e duas mulheres) com o intuito de definir o perfil dos entrevistados. Os dados levantados nessa etapa da pesquisa revelaram média de idade de 30,8 anos, onde $40 \%$ estão cursando ensino superior e outros $40 \%$ já finalizaram um curso de graduação; todos os entrevistados ocupam cargos de nível operacional na organização, e a média de tempo de contrato laboral com a empresa é de 6 anos.

Por meio das entrevistas foi possível identificar técnicas relacionadas ao endomarketing que a empresa utiliza, onde foram mencionados pelos indivíduos as ferramentas intranet, workplace, workchat e e-mails vinculados, as reuniões mensais, reuniões de engajamento, e comunicação aberta informal dentre os componentes do time de trabalho, conforme extratos dos discursos de E1, E2 e E3 abaixo:

E1: "No caso, a empresa geralmente tem, como posso dizer, palestras, alguns cursos sobre encantamento para que a gente sempre saiba como tratar clientes e funcionários, outras pessoas independentes disso. [...]. Nós temos as reuniões mensais como eu falei, que todo mês ocorre independente do que aconteça. E tem a do setor, que é uma vez ou outra. Na mensal, é passado as metas que a gente alcançou, se a gente conseguiu tudo certinho. E como eu disse, também tem a competição, entre as outras lojas, que a gente sabe a colocação em que ficamos no quadro, se foi um quadro positivo ou negativo. E tem as informais, com os gerentes, encarregados ou supervisor, que reúnem a equipe e dizem o que está acontecendo, onde precisa melhorar. E as vezes também, caso seja necessário, se está acontecendo algo com um colaborador, a gerência chama somente ele e o encarregado pelo setor para conversar em particular".

E2: "Nós temos um canal também aqui dentro, que nós chamamos de workplace, que seria um facebook da empresa, onde tudo o que acontece aqui dentro, é repassado lá. São 27 lojas, e todos os funcionários dessas 27 lojas conseguem ter essa visualização. E também você consegue interagir".

E3: "Sim, porque fora workplace em que podemos conversar com pessoas até de outra empresa, nós temos grupos, exemplos grupo de vendedores de móveis, onde a gente interage com todos os outros vendedores da empresa, solicitando produto, fotos, então a gente sempre tem contato direto não só com os funcionários daqui como das outras lojas, solicitando ajuda, principalmente sobre produtos para atender melhor o cliente”.

As informações passadas pelo discurso dos entrevistados demonstram que a empresa objeto deste estudo desenvolve diversas atividades voltadas para a comunicação entre instituição e 
As Práticas de Endomarketing e a Percepção dos Funcionários de uma Empresa do Ramo Varejista de Móveis e Eletrodomésticos de Manaus

funcionários. O repasse de informações de forma rápida e aberta é enfatizado pelos funcionários, que mencionam a integração entre as várias sedes da organização. Essa afirmação se comprova pelas expressões "tudo o que acontece aqui dentro é repassado lá" e "a gente interage com todos os outros vendedores da empresa" utilizadas por E2 e E3, respectivamente. Contudo, o discurso de E1, por sua vez, indica que essa comunicação explícita adotada pela empresa gera rivalidade e competitividade entre as lojas, conforme fragmento "E como eu disse, também tem a competição, entre as outras lojas, que a gente sabe a colocação em que ficamos no quadro". Dessa forma, verifica-se que a principal estratégia de endomarketing utilizada pela empresa consiste na comunicação aberta e divulgação de atividades e metas para o público interno.

Ademais, observa-se nos fragmentos de discursos de E2 e E3, citados a seguir, uma percepção positiva das práticas que a empresa adota, de forma que auxiliam na capacitação, desempenho e convivência pela equipe.

E2: “Antigamente a gente tinha que nos deslocarmos do nosso local de trabalho para fazer treinamentos fora. Aí tinha todo aquele transtorno porque tu tinhas que ir num horário que não fosse difícil para ti, e aí tinha que ir para lá que é mais longe, se locomover e voltar para continuar tua jornada de trabalho. Hoje em dia não, é mais cômodo. Porque o que tu se [sic] deslocava daqui para lá, já acessível aqui mesmo. De repente não conseguiu naquele momento, mas aí vai passando de um para o outro e fica armazenado. Então é mais cômodo".

E3: "Sim, porque alguns deles são mais voltados para nossa área pessoal, eles usam também alguns meios para caso se você tiver alguma dificuldade chamam você para conversar, mostram seus números, alguns deles são treinados para incentivar a gente a correr atrás, tem premiações para quando consegue o nosso objetivo, a nossa cota. Eles sempre fazem algo para deixar você com mais vontade de trabalhar".

Essa abordagem se mostra importante, pois de acordo com Pasquini (2015) esses fatores estão intrínsecos ao endomarketing no sentido de estimular a participação de todos os colaboradores na organização, por meio da identificação de suas necessidades e desejos para satisfazê-los, além de atrair e desenvolver talentos. Nesse sentido, a facilitação promovida pela empresa é vista pelos funcionários como melhoria quando dizem "hoje em dia é mais cômodo" ao se referirem ao método de treinamentos online, e "eles sempre fazem algo para deixar você com mais vontade de trabalhar" ao se referirem a atenção dispensada pelos superiores às necessidades dos subordinados.

Outra constatação obtida com a realização das entrevistas ressalta a influência da prática do endomarketing na agregação de valor para o cliente interno. Rodrigues (2017) diz que esta atitude é importante para a empresa pois ajuda na motivação para o trabalho, fazendo com que este se sinta recompensado em outras formas além de remuneração monetária. Barth e Negri (2012) afirmam que a agregação de valor é a tentativa de encantar o cliente interno, o que constitui um dos maiores desafios contemporâneos para as empresas, pois o envolvimento do funcionário possui impacto benéfico nas tarefas realizadas por este. Em concordância ao discurso dos autores, os sujeitos E2, E4 e E5 aduzem sentir que sua carreira profissional foi diretamente acrescida pela empresa, conforme os trechos seguintes.

E2: "Sim. Não por ela ser uma empresa pioneira no nosso estado, mas também porque ela te dá oportunidades, capacitação. E tem um daqueles pilares que eu te falei que é a melhoria contínua. Então ela te dá oportunidades de crescer, de tu ter [sic] o teu crescimento pessoal e profissional. Porque aqui, acontece uma espécie de lapidação.

UFAMBR, Manaus, v. 2, n. 2, art. 1, pp. 01-19, janeiro-junho, 2020 http://www.periodicos.ufam.edu.br/ufambr 
As Práticas de Endomarketing e a Percepção dos Funcionários de uma Empresa do Ramo Varejista de Móveis e Eletrodomésticos de Manaus A gente aprende a olhar as pessoas de uma outra forma. O teu pensamento de um jeito,
a gente aprende a tu ter [sic] uma visão diferenciada. Então para mim, ela me agregou
sim valores, e é uma grande satisfação com certeza".

E4: "Eu já estou na empresa há 8 anos, e nesses 8 anos eu já aprendi muito. A empresa, ela, vamos dizer que ela lapida as pessoas, os colaboradores dela. Entra de uma forma, e com o passar do tempo a gente consegue ver que aquela pessoa não é mais aquela que entrou, daquela forma. Até porque possuem os cargos, e a própria empresa ela zela por isso, de entrar num cargo e depois ir subindo e subindo. Então, assim, para mim, com certeza, $100 \%$. Com treinamentos, cursos, palestras. Isso enriquece muito. E posso te dizer que foi $100 \%$ proveitoso nisso".

E5: "Acho que sim, ponto positivo. Falo pessoas com quem eu já trabalhei que hoje não estão mais aqui. Vejo como positivo porque eles sempre falam que quando vão fazer uma entrevista o nome da empresa é uma referência, porque sabem que dão treinamento, fazem diversas coisas para capacitar a gente lá dentro".

A longa permanência na empresa e a convivência profissional prolongada com jornadas de trabalho estendidas também é vista de forma positiva entre os funcionários, pois cria a sensação de pertencimento à empresa e constituição de família entre o corpo de colaboradores. Essa afirmativa é corroborada pelos fragmentos dos discursos de E2, E3 e E4 abaixo:

E2: “Aqui dentro, tem períodos que a gente passa mais de $12 \mathrm{~h}$ por dia, querendo ou não, a gente já diz que aqui é a nossa primeira casa, porque a outra a gente só vai para dormir e voltar. [...] Quando a gente passa muito tempo num local, a gente querendo ou não, já passa a ter um vínculo afetivo, passa a ter uma amizade bem maior".

E3: "Sim, até porque a maior parte do tempo a gente passa na empresa, então a gente acaba se tornando, os nossos colegas se tornam uma segunda família [...]”.

E4: "Hoje em dia, pode-se dizer que aqui é a nossa segunda casa, segunda família. Aqui nós passamos dia dos pais, dia das mães, natal, todas essas datas comemorativas passamos aqui dentro, e isso influencia $100 \%$ diretamente aqui, como se fosse a nossa família".

Por outro lado, a visão apresentada em estudos como Shoji, Souza, Farias, Vieira \& Progiante (2016) e Mocelin (2011) mostram que a permanência exagerada em local de trabalho pode causar diversas consequências negativas, dentre as quais estão doenças relacionadas ao trabalho, físicas e mentais. Os autores aduzem também que as jornadas de trabalho estão diretamente ligadas à produtividade dos funcionários, de modo que o prolongamento pode ser causador de estresse, desencadeando tais doenças nos funcionários. Tendo em vista o relato de conotação positiva das longas jornadas de trabalho por parte dos funcionários, é possível verificar que a empresa tem obtido sucesso no convencimento de seus funcionários e em cultivar a ideia de positividade quanto as jornadas exaustivas de trabalho.

Oliveira, Carvalho \& Rosa (2012) aduzem que a boa convivência entre os funcionários é componente importante para a continuidade de um bom clima organizacional na empresa. Dessa forma, o conteúdo citado anteriormente também denota que o clima dentro da empresa objeto deste estudo é favorável para o desempenho dos colaboradores. Os indivíduos E1 e E3, em seus discursos, contam como é a natureza do ambiente de trabalho na empresa.

E1: "Ajuda e muito, porque se você tem um ambiente bom, você trabalha bem [...]. Na nossa equipe, é um clima bem descontraído e liberal, porque o que a gente faz no nosso setor, dá para fazer o nosso trabalho até escutando uma música, a gente conversa 
As Práticas de Endomarketing e a Percepção dos Funcionários de uma Empresa do Ramo Varejista de Móveis e Eletrodomésticos de Manaus

e brinca, e isso mantém um astral muito legal no setor. [...] Quando a gente está muito sobrecarregado, ele para e conversa e brinca um pouco, justamente para quebrar o clima de estar muito tenso, aí a gente quebra o gelo e retorna ao trabalho bem melhor".

E3: “[...] Porque aqui sempre tem ajuda de um por outro, se você tem dificuldade e o outro tá ali, e quando não, a gente pode contar com os nossos membros de chefia, eles são bem acolhedores. [...] Sempre tão ali querendo saber se você veio trabalhar diferente, se chegou atrasado porque ta com algum problema, se tem algo que eles possam ajudar, encaminham a gente para o RH para conversar com psicólogo para saber se temos algum problema e em que eles podem ajudar".

Por sua vez, os discursos de E2 e E4, citados a seguir, comprovam a movimentação da empresa no sentido de fomentar o desenvolvimento de clima favorável. Luz (2001) apud Oliveira et al (2012) afirma que o clima organizacional é de interesse da empresa, devendo esta tomar providências para que seja desenvolvido um ambiente positivo, por meio de ações e pesquisas.

E2: "Como eu te falei, a partir do momento que a gente entra aqui, a gente tem uma coisa chamada diagrama cultural, que a gente se baseia muito nele, que é integridade, respeito, economia, energia e melhoria contínua. [...]. E a partir do momento em que ele se encontra nisso, é mais fácil a gente conseguir essa movimentação dentro do setor. [...] Daí você tem a base de que aqui é um lugar bom de se estar e bom de se trabalhar".

E4: “Até porque por termos cargos diferentes, tanto do mais alto quanto do mais baixo, sem restrição alguma, essa parte de endomarketing acaba nos deixando todos no mesmo nível, entendeu? [...] Não tem diferença, por estarmos sempre participando de reuniões e pesquisa de clima, isso faz com que todos nós ficamos no mesmo nível”.

O endomarketing tem como principal estratégia que a comunicação seja bem difundida dentre os funcionários da empresa, tendo todas as partes interessadas em um objetivo, para que haja um desenvolvimento melhor do trabalho. A boa difusão da comunicação, utilizando as técnicas de endomarketing, ajuda na motivação dos funcionários e no engajamento para o trabalho (Brum, 2010).

Nesse sentido, a empresa tem obtido um bom resultado ao empregar ferramentas que possibilitam e facilitam a divulgação de informações dentro dos setores para todos os funcionários. Conforme descrito pelos entrevistados, os principais meios usados pela empresa são formalmente reuniões mensais e plataforma virtual workplace, e comunicação informal pessoal e virtual.

Tendo esses formatos, que já foram caracterizados anteriormente, evidencia-se que o repasse de informações dentro da empresa é eficaz, pois as opiniões coletadas fazem afirmações de ser eficiente, ter influência direta sobre a execução do trabalho, e melhorar o engajamento. Os relatos de E1, E3 e E5 reafirmam a caracterização dessa característica da empresa como ponto forte:

E1: "Temos sim, temos 3 meios de comunicação. Temos a intranet, temos um facebook próprio e temos os nossos gmails também, que são vinculados [...]. Ajuda muito, em caso de ideias e melhorias, tanto para loja quanto para empresa ajuda muito. [...] tanto que até outros colegas já deram opiniões lá nos nossos meios de comunicações e foram atendidos. [...] eles atendem muito bem a gente, independente do que seja, eles sempre estão lá para nos escutar". 
As Práticas de Endomarketing e a Percepção dos Funcionários de uma Empresa do Ramo Varejista de Móveis e Eletrodomésticos de Manaus

E3: "A nossa chefia sempre procura uma comunicação para ajudar, se eles veem que
algo está prejudicando em alguma coisa, eles chamam ou os vendedores ou toda loja,
conversam para que isso venha causar um impacto positivo, para que a gente possa
melhorar em alguma área que não esteja tão boa, porque eles sempre fazem algo para
melhorar a imagem da empresa. Tanto que sempre temos treinamento de como tratar
bem o cliente. Porque no nosso logotipo agora, o que está em primeiro lugar é a
satisfação dos clientes. Então eles sempre procuram conversar com a gente uma
maneira de melhorar para que todos os clientes saiam satisfeitos da loja".

E5: "Acho que é bom, a comunicação é boa para evitar conflitos, erros também, porque se não tiver comunicação, tudo é uma escala né, que a gente faz ali, começa ali em baixo, se desanda ali no meio, não vai para a frente. Então eu acho importante”.

A prática do endomarketing pela empresa busca incentivar o bom trabalho e o empenho, trazendo benefícios à empresa que faz uso desta ferramenta, pois atingir objetivos e cumprir metas é essencial para o sucesso e perenização de uma organização (Barth \& Negri, 2012). Conforme identificado nos discursos de E4 e E5 citados abaixo, é possível identificar a a movimentação da empresa no sentido de aplicar o endomarketing no âmbito de propaganda interna e comunicação facilitada, e nota-se também que os próprios funcionários reconhecem e aprovam a iniciativa.

E4: "Não, isso diretamente, posso te dizer que é muito bem visto né. Nós, com as nossas chefias temos muito, como eu citei na outra [pergunta], é tipo família direta. Então assim, o relacionamento é $100 \%$ com a gente. Somos abertos a falar o que pensamos, damos a nossa opinião quanto a vários assuntos que são perguntados e sugeridos. A empresa mesmo ela nos deixa dar sugestões, e as que são aproveitadas são premiadas."

E5: "Acredito que sim, acredito que faz bem essa parte, até porque é do próprio interesse dela né. Acho que é por isso que eles investem tanto em treinamento, em capacitação, sempre direcionando a gente para as metas, todo setor tem suas metas a serem cumpridas e a gente tem que bater todas elas. "

Quanto ao incentivo de proposição melhorias, somente os indivíduos E1, E2 e E5 indicam que há aperfeiçoamentos pendentes, pois na realidade de seu cotidiano, a empresa ainda não conseguiu atingir um patamar de excelência em funcionalidade, conforme o extrato das falas:

E1: "Acho que sim, porque sistema a gente pode sempre melhorar. Nenhum sistema, até de segurança, nenhum é perfeito. Então tem $\mathrm{N}$ fatores que dá para ser melhorado ali sim. Tanto que já chegamos a conversar com o próprio responsável pelo sistema da loja, e está para lá para resolver. A gente vai ver se vai dar certo ou não".

E2: “O que a gente estava buscando melhorar é só essa questão do chat né, que é uma sala de bate papo né, só que esse bate-papo, ele não é de colaborador para colaborador. A gente vai nele só para ver coisas de interesse tipo férias, contracheque e essas coisas. $\mathrm{O}$ que a gente colocou de melhoria, seria essa parte do bate-papo, porque a gente não consegue essa dinâmica. Às vezes eu preciso falar com alguém de uma loja e eu não consigo pelo telefone porque essa pessoa está ocupada, daí seria mais fácil porque ele começa a sinalizar que tem alguém querendo falar contigo. Então essa questão que a gente está ainda melhorando. Esse canal está sendo bem produtivo, de forma geral".

E5: “Ajudam e atrapalham um pouco ao mesmo tempo, porque quando colocam muita ferramenta juntos, é difícil você assimilar todas ao mesmo tempo. Mas de uma certa forma ajuda a contribuir bastante no trabalho, fica mais eficiente, prático, dinâmico, a comunicação das equipes fica melhor". 
As Práticas de Endomarketing e a Percepção dos Funcionários de uma Empresa do Ramo Varejista de Móveis e Eletrodomésticos de Manaus

A partir desses extratos, entende-se que a empresa precisa investir primordialmente no seu sistema de informação, que conforme as expressões "Nenhum sistema, até de segurança, nenhum é perfeito" e "só que esse bate-papo, ele não é de colaborador para colaborador" de E1 e E2, existem pendências a serem resolvidas relacionadas às funções em cada ferramenta disponibilizada para uso dos colaboradores, uma vez que nem todas as demandas foram atendidas até o momento. O indivíduo E5 ressalta que falta instrução quanto ao uso dessas ferramentas, pois conforme o extrato "porque quando colocam muita ferramenta juntos, é difícil você assimilar todas ao mesmo tempo", o excesso de informações pode ocasionar confusão.

Não foi evidenciado nos fragmentos as vantagens explícitas reconhecidas pelos funcionários a partir da aplicação dessas técnicas pela empresa.

\section{CONSIDERAÇÕES FINAIS}

O objetivo deste artigo foi avaliar a influência das práticas de endomarketing sob a ótica dos colaboradores de uma empresa do ramo varejista de móveis e eletrodomésticos na cidade de Manaus. Para realização do estudo, foi operacionalizada uma pesquisa qualitativa na qual os dados foram coletados por meio de entrevistas com roteiro semiestruturado. Os sujeitos da pesquisa foram cinco funcionários do nível operacional.

Por meio dos depoimentos dos indivíduos foi possível constatar que a empresa utiliza como ferramentas auxiliares os espaços de intranet, workchat, workplace e e-mails vinculados, todos necessitando de conexão de internet para funcionamento. Quanto a prática real da comunicação entre empresa e funcionários, foram relatados os procedimentos de reuniões mensais para toda a equipe e reuniões de encantamento somente para vendedores, além da comunicação informal entre funcionários.

A percepção principal passada nos relatos dos funcionários foi favorável a empresa, pois os entrevistados aduziram ter seu trabalho diretamente impactado pela disponibilidade dessas ferramentas a partir da facilitação da conversa entre membros e até mesmo entre sedes diferentes da empresa. Contudo, também se mostrou evidente que os funcionários entrevistados não sentem aumento da motivação para o trabalho por conta desses instrumentos, uma vez que ao serem questionados a respeito das vantagens pessoais, não foram levantados pontos relevantes.

Foi possível verificar ainda que a empresa possui orientação para o cliente externo muito maior do que para o interno, pois em todos os discursos foi possível evidenciar o convencimento aplicado junto aos funcionários quanto ao empenho na satisfação do consumidor, pois os entrevistados se mostraram confusos quanto ao direcionamento das questões, que eram voltadas ao trabalhador, e não ao comprador. Entretanto, após entendimento das indagações, foram feitos relatos positivos quanto à remuneração e incentivos, treinamento e desenvolvimento e relacionamento entre a equipe e com a chefia.

Dessa forma, a prática de endomarketing da empresa sob a ótica dos seus funcionários se mostra positiva no quesito de promoção da comunicação, contudo, faltam investimentos e atitudes no âmbito de promoção da cultura da empresa, desenvolvimento e retenção de talentos e defesa da marca, para possibilitar a fidelização do cliente interno. 
As Práticas de Endomarketing e a Percepção dos Funcionários de uma Empresa do Ramo Varejista de Móveis e Eletrodomésticos de Manaus

Para estudos futuros, sugere-se a utilização de técnicas quanti-qualitativas, a fim de captar dados mais detalhados quanto a aplicação das práticas de endomarketing utilizados por empresas, bem como a utilização de amostragem proporcional ao quadro de funcionários da organização, ainda que a pesquisa esteja restrita a apenas um nível organizacional. Indica-se também a utilização de critérios para aceitabilidade ou exclusão do entrevistado, a fim de prevenir desvios nas respostas obtidas.

Essas recomendações foram feitas a partir das limitações encontradas na realização deste estudo, a citar o método qualitativo, que não preza pela quantidade dos sujeitos. Ressalta-se também que este estudo foi realizado sem utilização de observação direta do ambiente, o que pode ser um fator relevante nos resultados obtidos, uma vez que na análise de conteúdo utilizase somente dos discursos para interpretação, onde os resultados dependem diretamente daquilo que o entrevistado estiver disposto a compartilhar.

\section{REFERÊNCIAS}

Angeloni, M. T. (2010). Comunicação nas organizações da era do conhecimento. São Paulo: Atlas.

Bardin, L. (2011). Análise de conteúdo. São Paulo: Edições 70.

Barros, A. J. P. \& Lehfeld, N. A. S. (2014). Projeto de Pesquisa: Propostas Metodológicas. $23^{\circ}$ ed. Rio de Janeiro: Vozes.

Barth, M. \& Negri, A. (2012). Endomarketing: o desafio de fidelizar o cliente interno. Revista Temática, Ano VIII, n. 1, p. 1-22.

Bekin, S. F. (1995). Conversando sobre endomarketing. São Paulo: Maron Books.

Brum, A. M. (2010). Endomarketing de A a Z: como alinhar o pensamento das pessoas a estratégia da empresa. São Paulo: Integrare Editora.

Câmara, R. H. (2013). Análise de conteúdo: da teoria à prática em pesquisas sociais aplicadas às organizações. Revista Interinstitucional de Psicologia, v. 6, n. 2, p. 179-191.

Chaves, E. P. S., França, A. V. S. \& Carvalho, K. A. P. (2013). O endomarketing alinhado as estratégias de reconhecimento e valorização do capital humano nas organizações: uma análise bibliográfica. Revista de Administração e Negócios da Amazônia, v. 5, n. 1, p. 103-121.

Cobra, M. (2011). Administração de Marketing. 2 ed. São Paulo: Editora Atlas.

Duarte, R. A. (2014). Pesquisa sobre os diferenciais encontrados nos colaboradores de uma empresa que se utiliza das ferramentas do endomarketing. Universidade do Extremo Sul Catarinense.

Feitosa, Á. M. V., Santos, D. M. L. \& Almeida, Y. T. M. (2016). O Endomarketing Como Estratégia De Gestão E Crescimento Organizacional. Revista CESMAQ, v. 1, n. 1, p. 114.

Honorato, G. (2004). Conhecendo o marketing. Barueri, SP: Manole.

José, B. L. C. S. \& Rosa, A. T. R. O. (2012). O endomarketing como ferramenta estratégica de gestão. Revista de Ciências Gerenciais, v. 16, n. 24, 145-159.

Kotler, P. \& Keller, K. L. (2006). Administração de marketing. 12. ed. São Paulo: Pearson PrenticeHall.

Kruger, J. M., Santos, A. P., Torres, E. M., Lima, I. S. \& Martins, S. R. M. (2016). A importância da elaboração do plano de marketing: estudo de campo ao nível de empresas no município de Manacapuru - AM. Congresso Internacional de Administração, Natal RN. 
As Práticas de Endomarketing e a Percepção dos Funcionários de uma Empresa do Ramo Varejista de Móveis e Eletrodomésticos de Manaus

Las Casas, A. L. (2009). Marketing: conceitos, exercícios, casos. 8 ed. São Paulo: Atlas.

Matias-Pereira, J. (2012). Manual de Metodologia da Pesquisa Científica. $3^{\circ}$ ed. São Paulo: Atlas.

Matos, G. G. (2009). Comunicação empresarial sem complicação: como facilitar a comunicação na empresa, pela via da cultura e diálogo. $2^{\circ}$ ed. Revisada e ampliada. Barueri, SP: Manole.

Marchiori, M. (2008). Cultura e comunicação organizacional: um olhar estratégico sobre a organização. $2^{\circ}$ ed. Revisada e ampliada. São Caetano, SP: Difusão Editora.

Marconi, M. A. \& Lakatos, E. M. (2017). Fundamentos de Metodologia Científica. $8^{\circ}$ ed. São Paulo: Atlas.

Mendes, R. S. A. D. (2004). Endomarketing como ferramenta de comunicação com o público interno. Universidade Federal de Juiz de Fora.

Miguel, F. V. C. (2010). A entrevista como instrumento para investigação em pesquisas qualitativas no campo da linguística aplicada. Revista Odisseia - UFRN, n. 5, p. 1-11.

Mocelin, D. G. (2011). Redução da Jornada de Trabalho e Qualidade dos Empregos: Entre o Discurso, a Teoria e a Realidade. Revista de Sociologia e Política, v. 19, n. 38, p. 101119.

Ogden, J. R. \& Crescitelli, E. (2007). Comunicação integrada de marketing: conceitos, técnicas e práticas. Tradução Cristina Bacellar. $2^{\circ}$ ed. São Paulo: Pearson Prentice Hall.

Oliveira, D., Carvalho, R. J. \& Rosa, A. C. M. (2012). Clima Organizacional: Fator de Satisfação no Trabalho e Resultados Eficazes na Organização. IX Simpósio de Excelência em Gestão e Tecnologia, Rio de Janeiro, RJ.

Pádua, E. M. M. (2016). Metodologia da Pesquisa: Abordagem Teórico-prática. $18^{\circ}$ ed. Campinas: Papirus.

Pasquini, N. C. (2015). Endomarketing, Ferramenta que Estimula Produção e Motivação: estudo de caso. Revista Gestão, Inovação e Negócios, v.1, n. 1, p. 98-112.

Pimenta, M. A. (2004). Comunicação Empresarial: conceitos e técnicas para administradores. Campinas, SP. Editora Alínea.

Pinho, J. B. (2012). Comunicação em Marketing: Princípios da comunicação mercadológica. $11^{\mathrm{a}}$ ed. Campinas, SP: Papirus.

Raquel, I. (2016). Planejamento Estratégico com foco em endomarketing: o caso da Alvogeo Topografia Ltda. Universidade Federal de Santa Catarina.

Reis, T. A., Brugnerotto, T. R., Sevilha, I. C., Cremonesi, G. O. G. \& Oswaldo, Y. C. (2018). Endomarketing, liderança e comunicação: reflexos na organização. Revista Brasileira de Marketing, v. 17, n. 1, p. 128-138.

Rodrigues, I. G. S. (2017). A importância das ações de endomarketing para a valorização do capital humano e o crescimento das organizações. Revista Campo do Saber, v. 3, n. 2, p. 67-84.

Santos, J. A. \& Filho, D. P. (2017). Metodologia científica. $2^{\circ}$ ed. São Paulo: Cengage Learning.

Santos, D. M. L., Almeida, Y. T. M. A. \& Feitosa, Á. M. V. F. (2016). O endomarketing como estratégia de gestão e crescimento organizacional. Revista CESMAC, p. 1-14.

Seitz, H. M. (2005). O planejamento estratégico de marketing e o plano de negócios. Revista Eletrônica de Gestão de Negócios, v. 1, n. 3, p. 91-126.

Silva, C. H. G., Neto, J. T. A. \& Motta, E. F. R. O. (2017). Endomarketing: ferramenta essencial para o desenvolvimento organizacional. Publicado em Agosto de 2017, acessado em 19 de Março de $2019 . \quad$ Disponível em <http://www.administradores.com.br/artigos/academico/

endomarketing-ferramenta-essencial-para-o-desenvolvimento-organizacional/106429/> 
As Práticas de Endomarketing e a Percepção dos Funcionários de uma Empresa do Ramo Varejista de Móveis e Eletrodomésticos de Manaus

Silveira, B. O. \& Felizola, M. P. M. (2009). O diálogo como necessidade da comunicação organizacional e uma análise da organização sergipana Semear. XXXII Congresso Brasileiro de Ciências da Comunicação, Curitiba, PR.

Shoji, S., Souza, N. V. D. O., Farias, S. N. P., Vieira, M. L. C. \& Progianti, J. M. (2016). Proposta de melhoria das condições de trabalho em uma unidade ambulatorial: perspectiva da enfermagem. Escola Anna Nery, v. 20, n. 2, p. 303-309. 